\title{
BMJ Open Perceptions, experiences and expectations of physicians regarding the role of pharmacists in low-income and middle-income countries: the case of Tehran hospital settings
}

\author{
Fatemeh Alipour, Farzad Peiravian, Gholamhossein Mehralian
}

To cite: Alipour F, Peiravian F, Mehralian G. Perceptions, experiences and expectations of physicians regarding the role of pharmacists in lowincome and middle-income countries: the case of Tehran hospital settings. BMJ Open 2018;8:e019237. doi:10.1136/ bmjopen-2017-019237

- Prepublication history for this paper is available online. To view these files, please visit the journal online (http://dx.doi org/10.1136/bmjopen-2017019237).

Received 1 September 2017 Revised 22 December 2017 Accepted 3 January 2018
Check for updates

\section{Department of}

Pharmacoeconomics and Pharma Management, School of Pharmacy, Shahid Beheshti University of Medical Sciences, Tehran, Islamic Republic of Iran

Correspondence to

Dr Gholamhossein Mehralian; gmehralian@gmail.com

\section{ABSTRACT}

Objective Pharmacists play a pivotal role in the health continuum, and the perceptions and expectations of physicians towards pharmacists have been reported as a key factor in the interprofessional relationship. This study aimed to elicit the perceptions and expectations of physicians towards the role of pharmacists in hospitals to clarify the level of interaction between physicians and pharmacists in hospital settings.

Design A cross-sectional survey using a self-administered questionnaire was conducted to collect data in 2016.

Methods A cross-sectional study was carried out at 20 large government hospitals in Tehran Province. Data was collected using a questionnaire consisting of four sections. It includes a section on demographic profile and three sections to measure the perceptions of physicians towards pharmacists, the expectations of physicians and their experiences with pharmacists, respectively.

Results More than two-thirds of physicians (67.2\%) agreed that pharmacists were a reliable source of general drug information. The majority of physicians $(90.6 \%)$ expected pharmacists to advise their patients about the dose and administration of their medications. Almost half of the physicians $(51.6 \%)$ agreed that they were usually informed by pharmacists regarding potential problems in their prescriptions. Both senior and junior residents had the view that pharmacists would inform them if any potential problems with their prescriptions were discovered ( $\mathrm{P}=0.04)$.

Conclusion This study demonstrated that physicians had positive view on pharmacists' clinically defined roles and also accepted pharmacists as a valuable source of general drug information. However, the perceptions and expectations of physicians towards pharmacists did not match their real experience. Therefore, improving the awareness of physicians about the benefits of interprofessional collaboration with pharmacists seems to be a key step towards the implementation of pharmaceutical care practices in Iran.

\section{INTRODUCTION}

Providing healthcare services is a dynamic business that has undergone numerous
Strengths and limitations of this study

- To the best of our knowledge, this is the first study investigating the perceptions and expectations of physicians towards the role of pharmacists and the level of interaction between physicians and pharmacists in Tehran hospital settings.

- This study invited physicians from 20 large hospital settings to complete the survey.

- Our findings showed that physicians have good view on developing the role of hospital pharmacists particularly regarding the clinically defined roles.

- Our findings revealed that although physicians considered pharmacists as a valuable resource, their real experiences were not consistent with their positive attitudes.

changes in the past few decades, among which interprofessional collaboration and education have been greatly encouraged to improve patients' outcome. ${ }^{12}$ Traditionally, physicians diagnosed diseases and prescribed medications, while pharmacists compounded and dispensed them. In this regard, there are some reasons compelling mutual collaboration between physicians and pharmacists such as fast growth of medical as well as pharmaceutical sciences, interactions among medications and rapidly increasing costs of therapy. ${ }^{23}$ Hence, this traditional relationship between physicians and pharmacists can no longer ensure the safety, effectiveness and adherence to therapy. In other words, addressing increasingly diverse and complex problems requires an interdisciplinary collaboration in which pharmacists can play a major role in providing valuable contributions to patients' care. $^{45}$

The provision of pharmacotherapy for achieving definite outcomes (ie, the patients' quality of life) through preventing and 
resolving drug-related problems is the heart of the pharmaceutical care philosophy. ${ }^{36-9}$ This philosophy is now well understood worldwide as the primary responsibility of pharmacists. ${ }^{10}{ }^{11}$ Specifically, the successful implementation of pharmaceutical care, particularly in hospital settings, requires close cooperation between physicians and pharmacists. ${ }^{12}$ The more interaction physicians and pharmacists have, the more effective and less expensive pharmacotherapy will be. ${ }^{13} 14$ However, the recognition of pharmacists' role in low-income and middle-income countries (LMICs), such as Iran, has not been achieved mainly because the perception of pharmacists, as one of health professional counsellors, is not fully comprehended yet, while within developed countries like UK and USA pharmacists play a crucial role particularly in hospital settings. ${ }^{14}$

Although some previous studies on physicians-pharmacists collaboration have highlighted that this collaboration was not well matured, ${ }^{1415}$ recent studies indicated that the role of pharmacists in improving patients' care in both hospital and outpatient settings has significantly improved. ${ }^{12} 16$ Nevertheless, in LMICs, the pharmacy profession encounters some challenges such as the dire shortage of qualified pharmacists and lack of standard practice guidelines. ${ }^{17}$ In addition, it is generally perceived by pharmacists that physicians are one of the major obstacles for expanding the roles of pharmacists in those countries. ${ }^{18}$ From another perspective, the most common negative experiences of physicians with pharmacists were reported to be that pharmacists may provide inappropriate drug information, dispense unauthorised refills and/or make inappropriate comments for patients. ${ }^{19}$ All of the aforementioned issues underline the need for a better collaboration between physicians and pharmacists for achieving better outcomes. ${ }^{20}$

\section{Pharmacy practice in LMICs}

One of the main goals of pharmacy practice is to improve the appropriate medications use. In comparison with developed countries, the healthcare systems and pharmaceutical sectors of LMICs are still unstable and in some countries they are backward. This might be owing to several underlying factors, and among which lack of effective health and pharmaceutical policies, lack of trained personnel and lack of financial support and resources are more important compared with others. Therefore, it is important to monitor these faults and the strategies taken by the country's authorities to enhance the situation. More details about pharmacy practice in Iran, as the context of this study, are outlined hereunder. ${ }^{9}$

Iran is a large country, with more than 80 million people, its population ageing has become a serious concern of the country within the last decades. The Ministry of Health plays a stewardship role in providing health services to the society through public and private sectors. ${ }^{21}$ Moreover, the Ministry of Health has recently experienced a great reform so as to increase the level of such services for individuals, particularly those who are socioeconomically frail. To this end, the government has made a great deal of effort to enhance the access of people to needed health services in right time with minimum cost. Among these efforts, providing pharmaceutical products available at affordable price is of great importance, which has indeed substantially reduced the patients' out-of-pocket expenses and increased their satisfaction. ${ }^{22}$ There is a consensus that pharmacists, as trustful specialists in pharmaceutical services, have a great potential to affect the outcome of treatment in either community pharmacies or hospital ones. ${ }^{7}$

With regard to pharmacy programme, pharmacy schools provide two degrees for students, including Pharm-D and PhD programmes. Within the former programme, the students mostly are trained to provide pharmaceutical care for societies, while in the latter programme the students are expected to be research oriented. This is mainly because the students who graduate from $\mathrm{PhD}$ programme have less interest to work in pharmacies, resulting in authorities allocating more resources to training undergraduate students. It is worth mentioning that, thanks to local scientists, particularly in the field of pharmaceutical sciences, Iran has shown a remarkable contribution to the production of knowledge over the world. ${ }^{23}$ Statistically speaking, it has been well documented that over $85 \%$ of graduated students select pharmacies for their future jobs ${ }^{24}$; hence, a major reform regarding pharmacy curriculum has occurred in the last years in order to provide more opportunities for students to be trained more socially regarding pharmaceutical care services. Specifically, this reform helps students to be well qualified, which means how appropriately they can communicate with patients, how they can influence the quality of pharmacotherapy as well as related services and how students would be clinically oriented in a hospital setting. With respect to hospital pharmacy, students have to experience clinical practice, particularly in communicating with both physicians and patients as to how they can play their role to increase the outcome of physicians' intervention. It should be stated that this reform is not well matured and takes time so that we can observe the effect of this acclaimed reform in the future. Nowadays, there are two types of pharmacists involving in Iranian hospital settings namely, hospital pharmacists and clinical pharmacists. In practice, hospital pharmacists mostly focus on providing pharmaceutical products rather than pharmaceutical care, while clinical pharmacists have been simply providing pharmaceutical care services for physicians during the last decade, and such qualified pharmacists have been undoubtedly influential in proposing cost-effective alternatives. It is expected that in the upcoming years, thanks to the mentioned reform, the hospital pharmacists (Pharm-D) would be able to join clinical pharmacists for increasing the powerful presence of pharmacists in clinical practice.

Finally, the main aim of this study was to elucidate the perceptions and expectations of physicians towards the role of pharmacists in hospital settings as well as the level 
of interactions between physicians and pharmacists in such settings.

\section{METHODS}

A cross-sectional survey was conducted at 20 large, government hospitals in Tehran between October 2015 and August 2016. Data was collected from residents and specialist physicians working at such hospital settings.

\section{Questionnaire development}

The self-administrated questionnaire used in this study was adopted from previously published studies with minor modifications. ${ }^{25-33}$ There were four sections in the questionnaire. Section 1 depicted the participants' demographic profile such as their current area of practice, current position, the country where qualification was obtained, the frequency of interacting with pharmacists and a description of the reason of this interaction. Section 2 measured the perceptions of physicians towards pharmacists. Sections 3 and 4 assessed the expectations of physicians and their experiences with pharmacists, respectively. Taking face and content validity of the questionnaire into account, we asked a group of five pharmacists and five specialist physicians to scrutiny the initial version of the questionnaire and judge face as well as content validity of each item. In order to improve clarity and limit response bias, the questionnaire was piloted before the study. Within this phase, 50 physicians who were practising in government hospitals were invited, and the results of analysis indicated that the survey questionnaire was appropriate enough for the next step.

Specifically, the perception levels of physicians towards pharmacists' contributions were measured by using uncomfortable, moderately comfortable or comfortable for each item. Items on expectation and experience were self-reported on a four-point Likert scale (strongly disagree, disagree, agree or strongly agree). A three-point and four-point Likert scale was used in order to avoid confusion with the 'neutral' responses. All questions were closed-ended ones.

\section{Sampling and data collection}

A sample of 500 physicians was randomly selected from 20 large, government hospitals. These hospitals are educational centres with a great number of physicians who are interested in participating in such surveys. These circumstances assured us that finding a suitable sample for further analysis would be possible. With respect to sample size, our assumption was that the suitable percentage of physicians who were communicating with pharmacists is $50 \%$ (95\% CI and 5\% accuracy). As a result, using Raosoft software (http://raosoft.com/samplesize.html) a sample size of 385 was proposed for this study. ${ }^{34}$ To this end, first of all a list covering all physicians working at studied hospitals was prepared, then the simple probabilistic approach was used to select physicians. Finally, 500 physicians were invited to this study. The questionnaires were distributed by two pharmacy students in a face-to-face manner and were collected by them. In some cases, those pharmacists had to refer physicians later, and in other cases the physicians were not keen on participating in the study mainly because they were so busy. It is worth mentioning that the questionnaires were distributed to the physicians whose names were identified and delivered by the head of research team. Regarding non-response bias, although the demographic profile of those physicians who were not willing to participate in this study was not collected by research team, it was clear for us that those physicians were too busy to participate in such studies.

The hospitals were not equally represented in that the total number of selected physicians in each hospital was different. Before the initiation of the survey, the physicians were presented with an explanation of the research purpose, and their verbal consent to participate in the study was obtained. The SPSS V.18 was used to analyse the data. The frequency values and cross-analysis between different variables were performed. $\chi^{2}$ tests were used to determine if there is any significant association among nominal variables in order to analyse the relationship between perception as well as experience of physicians with their demographic profile.

\section{RESULTS}

Out of the 500 questionnaires distributed, 415 were completed by the end of the study. Around half of physicians were women $(54.7 \%)$ with a mean age of 36 years. The majority of physicians obtained their medical degree from local universities. Less than half of the physicians were junior residents (first-year or second-year residents; $43.6 \%$ ), while the remainder were senior residents (third-year or fourth-year residents; $31.4 \%$ ) or professors $(25.1 \%)$. Table 1 shows the demographics and other characteristics of the physicians.

About three-quarters $(76.3 \%)$ of the physicians declared that they rarely interacted with the pharmacists (table 2). The physicians who had interactions with the pharmacists stated that their interactions were related to queries about drug availability $(81.9 \%)$, medicine substitution $(44.3 \%)$, side effects $(41.1 \%)$, drug interactions $(37.6 \%)$ and drug dosage $(28.2 \%)$.

Table 3 shows the perception level of physicians interacting with the pharmacists who were performing specific tasks; the majority of physicians were comfortable $(60.3 \%)$ with the pharmacists providing patient education. With respect to providing patient education, there was a significant association between age and area of practice $\left(\mathrm{P}=0.001^{*}\right.$ and $\mathrm{P}=0.003^{*}$, respectively). In regard to this association, physicians between the ages of 36 and 46 years, and dermatologists were more comfortable with pharmacists providing patient education. Threefifths $(63.1 \%)$ of the physicians believed that pharmacists should not be given the right to provide repeat-medication independently. A significant association was found in regard to the current position and physicians' opinion 
Table 1 Demographics and relevant characteristics of physicians $(n=415)$

\begin{tabular}{lc}
\hline Variable & (\%) \\
\hline Gender & \\
\hline Male & 45.3 \\
\hline Female & 54.7 \\
\hline Age & \\
\hline$<35$ years & 70.0 \\
\hline 36-46years & 19.5 \\
\hline$>47$ years & 10.5 \\
\hline Country where medical qualification was obtained \\
\hline $\begin{array}{l}\text { Iran } \\
\text { Foreign countries }\end{array}$ & 98.3 \\
\hline Area of practice & 1.7 \\
\hline Internal medicine & \\
\hline Obstetrics and gynaecology & 26.7 \\
\hline Surgery & 14 \\
\hline Ear, nose and throat & 12.5 \\
\hline Dermatology & 311.8 \\
\hline Paediatrics & 10.1 \\
\hline Others & 7.1 \\
\hline Current position & 17.7 \\
\hline $\begin{array}{l}\text { Junior (first-year and second-year } \\
\text { resident) }\end{array}$ & 43.6 \\
\hline $\begin{array}{l}\text { Senior (third-year and fourth-year } \\
\text { resident) }\end{array}$ & 31.4 \\
\hline Professor & 25.1 \\
\hline
\end{tabular}

about pharmacists repeating medication independently; senior residents were more likely than others to believe that pharmacists should be allowed to provide repeat-medication independently $\left(\mathrm{P}=0.04^{*}\right)$. Nearly three-quarters $(71.4 \%)$ of the physicians were comfortable with pharmacists identifying and preventing prescription errors, and this finding was statistically significant $(\mathrm{P}=0.02 *)$ with

Table 2 Frequency and reasons for interactions between physicians and pharmacists

\begin{tabular}{lc}
\hline Frequency of interaction & (\%) \\
\hline Rarely & 76.3 \\
\hline Once a week & 19.5 \\
Once a day/more & 4.2 \\
\hline Reasons for interactions & $\mathbf{( \% )}$ \\
\hline Drug-availability enquiries & 81.9 \\
\hline Side effects enquiries & 41.1 \\
\hline Drug-alternative enquiries & 44.3 \\
Drug-dosage enquiries & 28.2 \\
Drug-interaction enquiries & 37.6 \\
\hline Others & 22.1 \\
\hline
\end{tabular}

respect to the area of practice. Dermatologists were more comfortable with pharmacists identifying and preventing prescription errors. About half of the physicians were comfortable $(54.0 \%)$ with pharmacists suggesting medications appropriate for pharmacotherapy. Nearly half of the physicians $(54.0 \%)$ believed that patients could attain a better outcome and that the physicians' workload could be minimised if pharmacists contribute to all aspects of pharmacotherapy. In addition, there is a significant difference $\left(\mathrm{P}=0.04^{*}\right)$ as to their area of practice; surgeons were more likely to believe this opinion.

The actual experience of physicians with pharmacists is shown in table 4 . The majority of physicians $(67.2 \%)$ indicated that pharmacists are a great source of general information. Nearly half of the physicians $(53.6 \%)$ disagreed when they were asked about whether the pharmacists regularly inform them about more cost-effective alternatives. Half of the physicians $(51.6 \%)$ stated that pharmacists usually informed them if they notice potential problems with their prescriptions. About one-third of physicians agreed that pharmacists frequently informed them that their patients had experienced some problems with their medications $(33.5 \%)$. With respect to experience, no positive association was seen between this variable and demographic profile of the participants.

The results showing the expectations of physicians towards the roles of pharmacists are listed in table 5 . The majority of physicians (90.6\%) expected pharmacists to inform their patients about the dosage and administration of their medications. In addition, the majority of physicians $(87.8 \%)$ also expected pharmacists to provide drug and health information to patients. A significant association was found between these two mentioned expectations and the age of physicians. In this regard, physicians between the ages of 35 and 46 years were more likely to agree with pharmacists informing their patients about the dosage and administration of their medications $\left(\mathrm{P}=0.03^{*}\right)$ and providing drug and health information $(\mathrm{P}=0.02 *)$.

\section{DISCUSSION}

The future role of hospital pharmacists in healthcare system, particularly in Iran, depends on the inclination and the initiative of pharmacists to become more active members of the healthcare team as well as on the perception of physicians towards the new patient-oriented roles of pharmacists. Therefore, an understanding of the perceptions of physicians concerning their present experience with pharmacists' services and their expectations is of great importance. This will contribute to developing different strategies to address major concerns and maximise benefiting from limited resources in healthcare system. Although similar studies have been thus far reported in this matter, the views and the results may be different according to local conditions and cultures. ${ }^{925-32}$

This study illustrated the perceptions of physicians towards pharmacists being involved in patient education, 
Table 3 Perceptions of physicians towards the roles of pharmacists

\begin{tabular}{|c|c|c|c|}
\hline Duties of pharmacists & $\begin{array}{l}\text { Comfortable } \\
\text { (tolerant) (\%) }\end{array}$ & $\begin{array}{l}\text { Moderately } \\
\text { comfortable, n (\%) }\end{array}$ & $\begin{array}{l}\text { Uncomfortable } \\
\text { (non-tolerant) (\%) }\end{array}$ \\
\hline "Pharmacists should contribute to managing medication side effects" & 71.8 & 25.8 & 2.4 \\
\hline "Pharmacists should involve in medication insurance program" & 64.8 & 32.1 & 3.1 \\
\hline "Pharmacists should monitor pharmacotherapeutic outcomes" & 60.3 & 30.3 & 9.4 \\
\hline "Pharmacists should advise patients as to drug interactions" & 57.8 & 33.8 & 8.4 \\
\hline $\begin{array}{l}\text { "Pharmacists should suggest physicians in selecting appropriate } \\
\text { medicines" }\end{array}$ & 54.0 & 33.4 & 12.5 \\
\hline $\begin{array}{l}\text { "Pharmacists should recommend the use of non-prescription } \\
\text { medications to patient" }\end{array}$ & 47.7 & 34.8 & 17.4 \\
\hline "Pharmacists should play an important role in patient care" & 19.5 & 54.0 & 26.5 \\
\hline $\begin{array}{l}\text { "A patient's outcome could be better and physicians' workload } \\
\text { could be minimized if pharmacists are fully involved in all aspects of } \\
\text { medication" }\end{array}$ & 16.4 & 54.0 & 29.6 \\
\hline $\begin{array}{l}\text { "Patients should have consultation with a pharmacist regarding their } \\
\text { medications" }\end{array}$ & 14.3 & 62.4 & 23.3 \\
\hline $\begin{array}{l}\text { "Pharmacists should have the opportunity to suggest generic } \\
\text { substitution" }\end{array}$ & 13.6 & 44.6 & 41.8 \\
\hline $\begin{array}{l}\text { "A majority of patients would be more compliant with their } \\
\text { medications if they have a consultation with a pharmacist" }\end{array}$ & 13.6 & 59.6 & 26.8 \\
\hline
\end{tabular}

suggesting the use of prescription medication to physicians and patients, detecting and preventing prescription errors, and managing prescription side effects, which have been similarly identified in other studies. ${ }^{1726-2831323536}$ In this study, the responses of physicians were largely positive when they were asked about some of their perceptions towards the roles of pharmacists. Specifically, more than two-thirds of the physicians $(67.2 \%)$ agreed that pharmacists were a reliable source of general drug information, while more than half of them had rare interaction with pharmacists. This finding is in line with a number of previous studies on this issue. $^{26-2835}$ Physicians agreed that patient counselling, such as informing about the dose and administration of their medication, possible adverse drug effects, and food and drug interactions, are very important services that should be provided by pharmacists. This is consistent with a study which concluded that physicians have appropriate attitudes towards pharmacists' intervention in promoting the outcome of pharmacotherapy. ${ }^{30}$ In addition, more than half of the physicians in our sample $(63.1 \%)$ were uncomfortable with pharmacists refilling medication independently. Previous studies have also reported the reluctance of physicians on pharmacists acting autonomously in regard to therapeutic choices. ${ }^{37}$ Some physicians apparently felt that this could be an incursion into their own realm and would damage the physician-patient relationship. ${ }^{37}$ Similar to some studies, for example, Yousefi et al, most of the physicians were dissatisfied with the pharmacists' suggestion to generic substitutions. ${ }^{38}$ This was mainly because some physicians believe that these activities call into their autonomy and authority or likely impair the physician-patient relationship if the pharmacist's recommendation differs from their own. However, pharmacist-led counselling was the only activity where physicians were not directly involved in the relationship, unless they were directly informed by patients as to whether they have been counselled or otherwise. As a consequence, physicians may simply have not been aware of this service, thereby mostly disagreeing with this point on counselling services by pharmacists. $^{25}$ This finding also shows that although physicians may agree with pharmacists providing consultative roles, they may be more uncomfortable with the 
Table 4 Actual experience of physicians with pharmacists

\begin{tabular}{|c|c|c|c|c|}
\hline Experiences of physicians & $\begin{array}{l}\text { Strongly } \\
\text { agree (\%) }\end{array}$ & Agree (\%) & Disagree (\%) & $\begin{array}{l}\text { Strongly } \\
\text { disagree }(\%)\end{array}$ \\
\hline $\begin{array}{l}\text { "Pharmacists routinely inform me if they notice potential problems in } \\
\text { my prescriptions" }\end{array}$ & 9.1 & 42.5 & 39.0 & 9.4 \\
\hline $\begin{array}{l}\text { "Pharmacists routinely inform me about more cost-effective } \\
\text { alternatives" }\end{array}$ & 8.0 & 38.3 & 44.9 & 8.7 \\
\hline $\begin{array}{l}\text { "In my experience, pharmacists are a trustworthy source of general } \\
\text { drug information" }\end{array}$ & 7.3 & 59.9 & 28.6 & 4.2 \\
\hline $\begin{array}{l}\text { "Pharmacists routinely advise my patients as to the safe and the } \\
\text { appropriate use of their medications" }\end{array}$ & 5.9 & 35.2 & 50.2 & 8.7 \\
\hline $\begin{array}{l}\text { "I create a relationship with pharmacists when the pharmacist try to } \\
\text { adjust my patients' medication" }\end{array}$ & 5.6 & 31.4 & 49.5 & 13.6 \\
\hline $\begin{array}{l}\text { "Pharmacists routinely let me know that my patients have } \\
\text { encountered some problems with their medications" }\end{array}$ & 4.2 & 29.3 & 53.7 & 12.9 \\
\hline $\begin{array}{l}\text { "In my experience, pharmacists tend to take personal responsibility } \\
\text { for managing any drug-related problems" }\end{array}$ & 3.8 & 32.8 & 50.5 & 12.9 \\
\hline $\begin{array}{l}\text { "Pharmacists regularly inquire me to clarify for them the } \\
\text { pharmacotherapy objectives that I have in my mind" }\end{array}$ & 3.5 & 28.6 & 52.3 & 15.7 \\
\hline
\end{tabular}

clinically defined roles of the pharmacists being involved in making decisions for patients independently. ${ }^{39}$ In addition, the majority of physicians were comfortable with pharmacists suggesting the use of non-prescription medications to patients. This finding is in agreement with other studies which highlighted the increasing number of medications that have been deregulated to over-the-counter status worldwide, thereby reducing costs and physicians' workload..$^{25-29} 32$ It is obvious that most LMICs face with lack of qualified pharmacists in terms of proposing cost-effective alternatives as well as how to deal with these issues in practice; hence, physicians are not willing to interact with such pharmacists in order to find a cost-effective alternative, resulting

Table 5 Expectations of physicians towards the roles of pharmacists

\section{Expectations of physicians}

\section{Strongly} agree (\%) Agree (\%)

"I expect pharmacists to inform my patients about probable adverse drug 39.0 reactions"

"I expect pharmacists to inform my patients about probable interactions" 38.

"I expect pharmacists to inform my patients about the dosage and admin 35.2 istration of their medications"

"I expect pharmacists to prepare a drug and health information pamphlet 30.7 to patients"

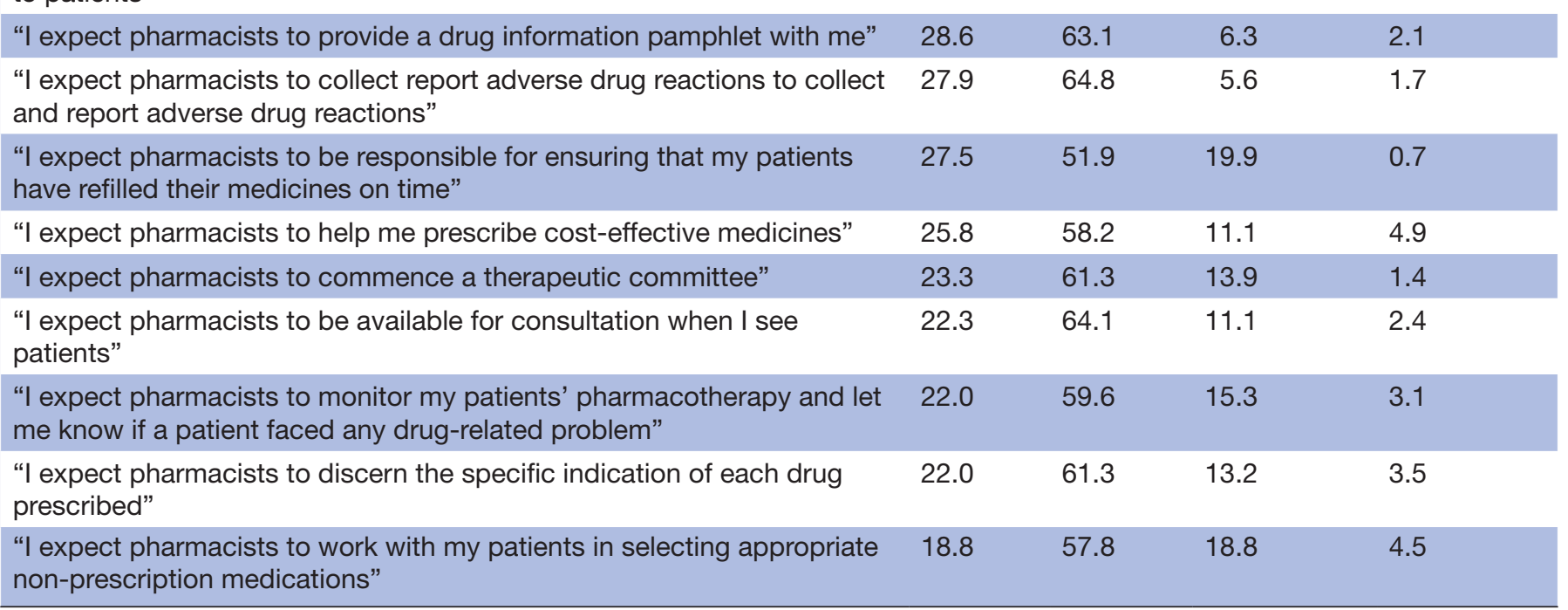

Strongly

$49.5 \quad 10.1 \quad 1.4$

$\begin{array}{lll}54.0 & 6.6 & 1.4\end{array}$

$\begin{array}{lll}55.4 & 8.7 & 0.7\end{array}$

$\begin{array}{lll}57.1 & 9.8 & 2.4\end{array}$

2.4 sagree (\%)

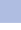

.7

4


in the rare contact of these two health professional in pharmacotherapy.

According to $\chi^{2}$ test, findings show that physicians, especially senior residents, have high expectations regarding the pharmacists' clinically defined roles. This may reflect that the level of pharmacy practice in the future should change to a patient-oriented fashion in such settings. ${ }^{41}$ In general, although physicians had a little experience about certain activities of pharmacists, the findings regarding the expectations of physicians on these new roles for pharmacists were promising. This is a promising insight in the light of the 'extended roles' of pharmacists and the emergence of such concepts as pharmaceutical care as well as good pharmacy practice. ${ }^{27}$ More specifically, the deficiency in the experience of physicians with pharmacists is the consequence of the rare interactions and inadequate number of pharmacists working in hospital settings. Statistic shows that only a small percentage of pharmacists are working in Tehran's hospitals and they are more focused on drug-oriented rather than patient-oriented pharmacy services in their practice. This approach causes the majority of the physicians in this study not to believe that pharmacists routinely counselled their patients with regard to safety and appropriate use of their medications and that these pharmacists were willing to take personal responsibility to resolve any drug-related problems they discover. These results were similar to a number of previously published studies. ${ }^{14}$ 25-27 42 These low experiences could be explained by the fact that most pharmacists have low confidence in participating in clinical decision processes. This can be due to a deficiency in the clinical content of the pharmacy curriculum. Therefore, Iranian pharmacists need to work more closely with physicians, thereby providing the physicians with an opportunity to observe pharmacists' clinical capabilities, and they should also make physicians more confident towards the roles of pharmacists.

\section{Limitation of study}

The results of this study cannot be generalised to all physicians as private hospitals and other non-educational ones were not included in the study. The views may be different among the physicians in hospital settings or in private sectors where the experiences and contacts with pharmacists may be different. A large study is recommended to extrapolate and generalise the results. This study investigated the perceptions, expectations and experiences of physicians and not that of pharmacists. Hence, a future study investigating the attitudes and experiences of pharmacists will give a more comprehensive view. Furthermore, the questionnaire consisted of only closedended questions, while the inclusion of some open-ended questions may help elucidate expectations or experiential problems, which were not specifically concerned in the questionnaire. Social desirability would not be a big concern in this study as in the majority of cases, physicians did not accept to answer the survey through a faceto-face approach.

\section{CONCLUSION}

This survey demonstrates that physicians were interested in developing pharmacists' roles and also contemplated pharmacists as a trustworthy source of drug information. However, the expectations and perceptions of physicians towards the roles of pharmacists did not match their real experience tackling with the latter. Greater efforts are required to increase the awareness of physicians with regard to the importance of collaboration among healthcare professionals in general and what benefits can be gained from this on patients' quality of life and healthcare cost in particular. It is also important to incorporate direct patient care during clinical rotations with physicians in the pharmacy educational programme. Taking rare contact among health professionals into account, collaborative learning between pharmacists and physicians is highly recommended for consideration within undergraduate and postgraduate educational programmes. This will promote the improved understanding of clinical pharmacists' roles by physicians and support interprofessional collaboration in identifying the shared goal of improving care for patients.

Contributors GM contributed to the conception and design, analysis and interpretation of data. FA contributed to collecting the data, drafting the manuscript and reviewing the manuscript. FP contributed to conception and design. All authors read and approved the final manuscript.

Funding This research received no specific grant from any funding agency in the public, commercial or not-for-profit sectors.

Competing interests None declared.

Patient consent Obtained.

Ethics approval Ethical approval was obtained for this study. However, following ethical concerns, a comprehensive description about the study was introduced to the participants in the first page of the questionnaire and they were allowed to reject answering or withdrawing at any time thereafter. The participants were assured that their answers would be kept confidential and that their names would not be disclosed during the study and in the final report. In addition, this study was approved by the ethics committee of Shahid Beheshti University of Medical Sciences with reference number: 66001048.

Provenance and peer review Not commissioned; externally peer reviewed.

Data sharing statement Data set might be available to the interested researchers on request from the authors. All questionnaires and data set were unpublished. GM has access to the data and can be contacted by: gmehralian@gmail.com.

Author note *All coefficients are significant at 0.05 .

Open Access This is an Open Access article distributed in accordance with the Creative Commons Attribution Non Commercial (CC BY-NC 4.0) license, which permits others to distribute, remix, adapt, build upon this work non-commercially, and license their derivative works on different terms, provided the original work is properly cited and the use is non-commercial. See: http://creativecommons.org/ licenses/by-nc/4.0/

C Article author(s) (or their employer(s) unless otherwise stated in the text of the article) 2018. All rights reserved. No commercial use is permitted unless otherwise expressly granted.

\section{REFERENCES}

1. Zillich AJ, Milchak JL, Carter BL, et al. Utility of a questionnaire to measure physician-pharmacist collaborative relationships. J Am Pharm Assoc 2006;46:453-8.

2. Hojat M, Gonnella JS. An instrument for measuring pharmacist and physician attitudes towards collaboration: preliminary psychometric data. J Interprof Care 2011;25:66-72. 
3. Zillich AJ, Doucette WR, Carter BL, et al. Development and initial validation of an instrument to measure physician-pharmacist collaboration from the physician perspective. Value Health 2005;8:59-66.

4. Bryant L, Coster G, McCormick R. General practitioner perceptions of clinical medication reviews undertaken by community pharmacists. J Prim Health Care 2010;2:225-33.

5. Carter BL, Rogers M, Daly J, et al. The potency of team-based care interventions for hypertension: a meta-analysis. Arch Intern Med 2009;169:1748-55.

6. Hepler CD, Strand LM. Opportunities and responsibilities in pharmaceutical care. Am J Hosp Pharm 1990;47:533-43.

7. Mehralian G, Rangchian M, Rasekh HR. Client priorities and satisfaction with community pharmacies: the situation in Tehran. Int $J$ Clin Pharm 2014;36:707-15.

8. Stemer G, Laml-Wallner G, Kuegler I, et al. Comprehensive evaluation of clinical pharmacists' interventions in a large Austrian tertiary care hospital. Eur J Hosp Pharm 2012;19:529-34.

9. Mehralian G, Rangchian M, Javadi A, et al. Investigation on barriers to pharmaceutical care in community pharmacies: a structural equation model. Int J Clin Pharm 2014;36:1087-94.

10. Rovers JP. A practical guide to pharmaceutical care: APhA Publications, 2003

11. Khalili H, Farsaei S, Rezaee H, et al. Role of clinical pharmacists' interventions in detection and prevention of medication errors in a medical ward. Int J Clin Pharm 2011;33:281-4.

12. Chen TF, de Almeida Neto AC. Exploring elements of interprofessional collaboration between pharmacists and physicians in medication review. Pharm World Sci 2007;29:574-6.

13. Martin S. In the physician's office: an interview with W. Ray Burns. Am Pharm 1989;NS29:17-19.

14. Fortner $\mathrm{C}$. Building cooperation with physicians: an interview with Charles Fortner. Interview by Joyce Leinberger Mitchell. Am Pharm 1990;NS30:24-6.

15. Smith WE, Ray MD, Shannon DM. Physicians' expectations of pharmacists. Am J Health Syst Pharm 2002;59:50-7.

16. Sorensen L, Stokes JA, Purdie DM, et al. Medication reviews in the community: results of a randomized, controlled effectiveness trial. $\mathrm{Br}$ J Clin Pharmacol 2004;58:648-64.

17. Ranelli PL, Biss J. Physicians' perceptions of communication with and responsibilities of pharmacists. J Am Pharm Assoc 2000:40:625-30.

18. Sing WS. Pharmacy practice in Malaysia. Malaysian $J$ Pharm 2001;1:3-9.

19. Aburuz S, Al-Ghazawi M, Snyder A. Pharmaceutical care in a community-based practice setting in Jordan: where are we now with our attitudes and perceived barriers? Int $J$ Pharm Pract 2012;20:71-9.

20. Sabry NA, Farid SF. The role of clinical pharmacists as perceived by Egyptian physicians. Int J Pharm Pract 2014;22:354-9.

21. Shabaninejad H, Mehralian G, Rashidian A, et al. Identifying and prioritizing industry-level competitiveness factors: evidence from pharmaceutical market. Daru 2014;22:35

22. Mehralian G, Nazari JA, Zarei L, et al. The effects of corporate social responsibility on organizational performance in the Iranian pharmaceutical industry: The mediating role of TQM. J Clean Prod 2016;135:689-98.
23. Jiménez Cisneros B. The data gap. Nature 2013;502:633-4

24. Foroughi Moghadam MJ, Peiravian F, Naderi A, et al. An Analysis of Job Satisfaction among Iranian Pharmacists through Various Job Characteristics. Iran J Pharm Res 2014:13:1087-96.

25. Awad A, Matowe L, Capps P. Medical doctors' perceptions and expectations of the role of hospital pharmacists in Sudan. Pharm World Sci 2007;29:557-64.

26. Tahaineh LM, Wazaify M, Albsoul-Younes A, et al. Perceptions, experiences, and expectations of physicians in hospital settings in Jordan regarding the role of the pharmacist. Res Soc Adm Pharm 2009;5:63-70.

27. Zaidan $M$, Singh R, Wazaify M, et al. Physicians' perceptions, expectations, and experience with pharmacists at Hamad Medical Corporation in Qatar. J Multidiscip Healthc 2011;4:85-90.

28. Azhar S, Hassali M, Ibrahim M. Doctors' perception and expectations of the role of the pharmacist in Punjab, Pakistan. Trop J Pharm Res 2010;9.

29. Khdour MR, Alayasa KS, AlShahed QN, et al. Physicians' perceptions, attitudes and expectations regarding the role of hospital-based pharmacists in the West Bank, Palestine. Int J Pharm Pract 2013;21:178-84.

30. Bailie GR, Romeo B. New York State primary care physicians' attitudes to community pharmacists' clinical services. Arch Intern Med 1996;156:1437-41.

31. Awalom MT, Kidane ME, Abraha BW. Physicians' views on the professional roles of pharmacists in patient care in Eritrea. Int $\mathrm{J}$ Clin Pharm 2013;35:841-6.

32. Kelly DV, Bishop L, Young S, et al. Pharmacist and physician views on collaborative practice: Findings from the community pharmaceutical care project. Can Pharm J 2013;146:218-26.

33. Matowe L, Abahussain EA, Al-Saffar N, et al. Physicians' perceptions and expectations of pharmacists' professional duties in government hospitals in Kuwait. Med Princ Pract 2006;15:185-9.

34. Chap L, designs S. In: Chap L, ed. Introductory Biostatistics, 1st edn Hoboken, NJ: JohnWiley \& Sons 2003:445-570.

35. Hamadi SA, Mohammed MM, Dizaye KA, et al. perceptions, experiences and expectations of physicians regarding the role of the pharmacist in an iraqi hospital setting. Trop $J$ Pharm Res 2015;14:293-301.

36. Khdour MR, Alayasa KS, Alshahed QN, et al. Physicians' perceptions, attitudes and expectations regarding the role of hospital-based pharmacists in the West Bank, Palestine. Int J Pharm Pract 2013;21:178-84.

37. Bradshaw SJ, Doucette WR. Community pharmacists as patient advocates: physician attitudes. J Am Pharm Assoc 1998;38:598-602.

38. Yousefi N, Mehralian G, Peiravian F, et al. Physicians' perceptions of generic medicine in Iran. Drugs \& Therapy Perspectives 2015;31:244-50.

39. Lobas NH, Lepinski PW, Woller TW. Satisfaction of physicians and nurses with clinical pharmacy services. Am J Hosp Pharm 1991;48:1189-90.

40. Ritchey FJ, Raney MR. Effect of exposure on physicians' attitudes toward clinical pharmacists. Am J Hosp Pharm 1981;38:1459-63.

41. Barnett NL, Flora K. Patient-centred consultations in a dispensary setting : a learning journey, 2016:1-3.

42. Cowen DL. Changing relationship between pharmacists and physicians. Am J Hosp Pharm 1992;49:2715-21. 